\title{
KEANEKARAGAMAN JENIS POHON PADA DAERAH KARST SANGKULIRANG MANGKALIHAT KALIMANTAN TIMUR
}

\author{
Dzulkipli $^{1}$, Paulus Matius ${ }^{2}$, dan Chandradewana Boer $^{3}$ \\ ${ }^{1}$ Kehutanan, Fakultas Kehutanan, Universitas Mulawarman, J1 Ki Hajar Dewantara \\ Kampus Gunung Kelua, Samarinda, Kalimantan Timur, Indonesia. \\ E-Mail: zsyam73@gmail.com
}

\begin{abstract}
ABSTRAK
Keanekaragaman Jenis Pohon Pada Daerah Karst Sangkulirang Mangkalihat Kalimantan Timur. Kawasan Karst Sangkulirang Mangkalihat merupakan pegunungan karst terbesar di Kalimantan Timur, terletak di Kabupaten Kutai Timurdan Kabupaten Berau dengan total luas keseluruhan 1.867.676 hektar. Penelitian ini dilakukan untuk menganalisis keanekaragaman jenis vegetasi tingkat pohon di beberapa komunitas karst. Areal penelitian ditentukan secara purposive dan sistematik sampling. Berdasarkan hasil penelitian ini, spesies tanaman yang ditemukan sebanyak 162 jenis. Potensi vegetasi terbesar terdapat di Gunung Gergaji dengan nilai individu 740/ha, Indeks keragaman jenis tergolong tinggi dengan nilai 3.173.51 .
\end{abstract}

Kata kunci : Karst, Keanekaragaman, Sangkulirang Mangkalihat, Vegetasi.

\section{ABSTRACT}

Tree Biodiversity on the Sangkulirang Mangkalihat karst area, East Borneo. arst area on Sangkulirang Mangkalihat is the biggest Karst mountains in East Borneo, located in East Kutai and Berau district with extensive 1.867.676 ha. This research do to analyze the species biodiversity tree level vegetation in several karst community. The research area determined on purposive and systematic sampling. According this research result, plant species that founded as much as 162 species. The biggest vegetation potention founded on Gergaji Mountain with individual value 740/ha. Biodiversity index is high with value 3.17-3.51.

Key words : Kasrt, Biodiversity, Sangkulirang Mangkalihat, Vegetation.

\section{PENDAHULUAN}

Kawasan karst merupakan bentangalam khas dengan kekayaan sumberdaya alam tinggi (Raguz, 2008). Karst terbentuk akibat proses pelarutan (solusional) pada batuan mudah larut seperti karbonat, gypsum, dan batu garam (Haryono \& Adji, 2004).Kondisi lingkungan tertentu, setiap jenis tumbuhan tersebar dengan tingkat adaptasi yang beragam, sehingga menyebabkan hadir atau tidaknya suatu jenis tumbuhan pada lingkungan tersebut. Hasil penelitian lain menunjukkan bahwa faktor lingkungan dapat mempengaruhi struktur dan komposisi vegetasi yang terbentuk di suatu kawasan. Salah satu faktor lingkungan yang dapat mempengaruhi suatu komunitas vegetasi adalah ketinggian tempat. Ketinggian tempat memiliki pengaruh yang sangat kuat terhadap persebaran jenis pohon(Kurniawan dan Parikesit 2008).Kawasan karst merupakan sumberdaya alam tidak terbaharukan dengan fungsi dan potensi sumberdaya alam yang tinggi (Beynen \& Townsend, 2005).Para ahli ekologi hutan mengelompokkan hutan bukit kapur sebagai satu ekosistem hutan sendiri (Van,Stenis : Achmad, 2011).Fungsi dan potensi karst bagi makhluk hidup khususnya manusia dikelompokkan menjadi 3 aspek, yaitu: aspek ekologis, 
hidrologis, dan sosial budaya (Haryono \& Sutikno, 2000).

\section{METODA PENELITIAN}

\subsection{Tempat dan Waktu}

Penelitian ini dilaksanakan di Kawasan Karst SangkulirangMangkalihat Kabupaten Beraudan Kabupaten Kutai Timur Provinsi Kalimantan Timur. Waktu penelitian ini dilaksanakan selama 6 bulan.

2.2. Bahan dan Alat

Bahan yang digunakan dalam penelitian ini, antara lain Alkohol $70 \%$, untuk proses pengawetan sampel herbarium, Pita Survei, untuk batas plot dan sebagai label vegetasi yang akan di amati, Kantong Plastik, untuk memasukkan sampel herbarium, Kertas Koran, untuk membungkus sampel yang akan di herbarium, Tali tambang/ raffia, untuk member tanda jalur plot. Sedangkan alat yang digunakan adalah Tallysheet, untuk mencatat data yang telah di peroleh, Meteran, untuk mengukur jarak, Patok, untuk memberi tanda plot Kompas, untuk menentukan arah jalur, GPS, untuk menentukan lokasi penelitian dan titik koordinat lokasi penelitian, Parang, untuk membuat jalur, Clinometer, untuk mengukur kelerengan lokasi penelitian, Buku identifikasi digunakan sebagai alat bantu untuk mengenali jenis pada saat penelitian, Kamera, untuk dokumentasi, Buku Milimeter blok, digunakan untuk membuat posisi pohon dan proyeksi tajuk pada saat dilapangan Oven dan sasak, digunakan untuk mengeringkan sampel, sedangkan sasak digunakan sebagai alat press pada saat pengovenan, Kamera digital, digunakan sebagai alat bantu dokumentasi dalam penelitian.

\subsection{Prosedur Penelitian}

2.3.1. Orientasi Lapangan

Kegiatan ini bertujuan untuk menentukan jalur dan letak pembuatan plot pengamatan agar memenuhi kriteria sesuai dengan tujuan penelitian.

\subsubsection{MetodePenelitian}

Penelitian ini dilaksanakan dengan menggunakan metode analisis vegetasi dengan menggabungkan metode Purposive dan sistematik sampling pad lembah, lereng dan punggung bukit karst (3 jalur) yang secara keseluruhan mewakili kondisi topografi yang ada, penerapan metode ini mengikuti karakter lokasi penelitian yang di dominasi oleh batuan kapur.

\subsubsection{Pembuatan Plot Penelitian}

Plot penelitian dibuat pada 6 (enam) lokasi yaitu Suaran, Tondoyan, Gergaji, Biatan, Lubang Klatak dan Biduk-biduk. Pada masing-masing kelas topografi dibuat plot berukuran $10 \mathrm{~m} \times 10 \mathrm{~m}$, dengan pertimbangan kondisi topografi di daerah punggung, lereng dan lembah. Setiap lokasi terdapat 15 buah plot yang terdapat pada 3 jalur (5 plot/ jalur), Sehingga jumlah keseluruhan plot adalah 90 buah (pada masing masing komunitas terdapat 15 plot). Adapun gambaran tata letak sub plot dalam plot pengamatan dapat dilihat pada gambar dibawah ini: 


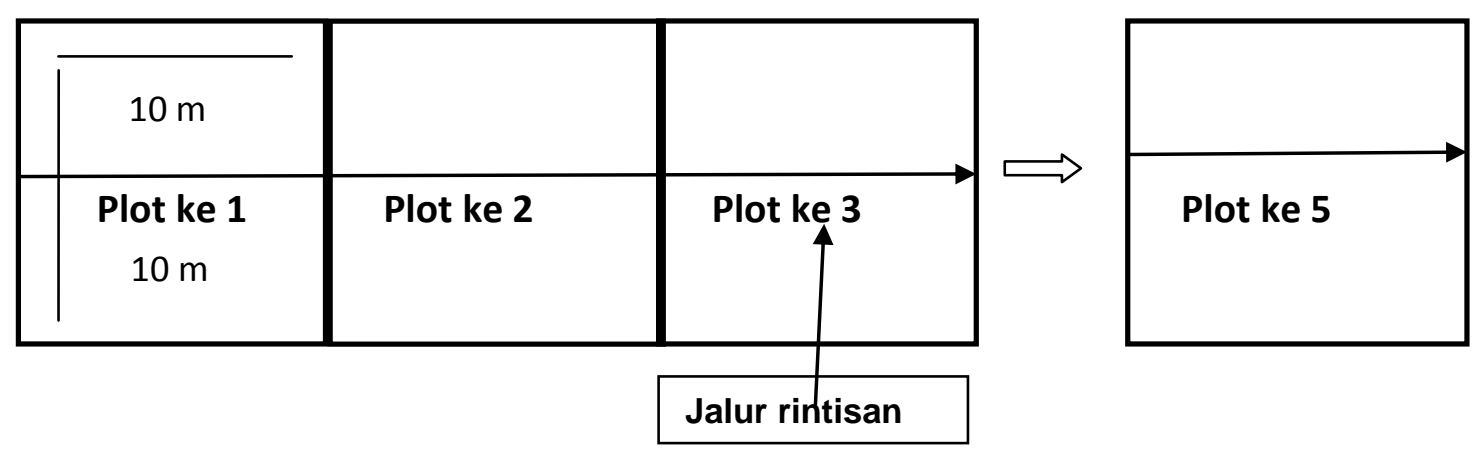

Gambar 1. Desain Plot Penelitian

\subsection{Pengolahan Data}

Menghitung Indeks keanekaragaman Jenis

Vegetasi bisa terdiri beragam jenis, atau hanya beberapa jenis atau seragam. Untuk mengukur keragaman suatu komunitas vegetasi digunakan rumus indeks keragaman. Rumus yang paling umum dipakai adalah Shannon-Wiener sebagai berikut (Krebs, 1985) ; Magurran 1988 dalam Indriyanto 2006)
Dimana :

$$
\mathrm{H}^{\prime}=-\sum \frac{n i}{N} \log \frac{n i}{N}
$$

$$
\begin{aligned}
& \mathrm{H}^{\prime}=\text { indeks keragaman Shannon }- \text { Wiener } \\
& \text { ni }=\text { Jumlah individu dari satu jenis } \mathrm{i} \\
& \mathrm{N}=\text { Jumlah total individu seluruh jenis } \\
& \log =\log \text { natural/naperian }=2,178 \ldots
\end{aligned}
$$

Kriteria indeks keanekaragaman jenis (diversitas) dapat dilihat pada tabel di bawah ini:

Tabel 1. Kriteria Indeks Keanekaragaman Jenis

\begin{tabular}{cc}
\hline Kriteria & Indeks Keanekaragaman Jenis \\
\hline Tinggi & $>3$ \\
Sedang & $2-3$ \\
Rendah & $0-2$ \\
\hline
\end{tabular}

Sumber : Barbour et al., (1987)

Menurut Magurran 1988 dalam Boer 1994 Dari nilai keragaman (H') dapat dihitung besarnya varian sebagai berikut :

$$
\operatorname{Var}\left(\mathrm{H}^{\prime}\right)=\sum_{i=1}^{s} p i \frac{p i(\ln p i)^{2}-(H v)^{2}}{N}+\frac{s-1}{2 N^{2}}
$$

Keterangan :

Var H' : Varian keanekaragaman jenis

$\mathrm{Pi}:$ ni/N

$\mathrm{N} \quad$ : Total jumlah individu

$\mathrm{S} \quad$ : Jumlah jenis
Dengan menggunakan uji-t dua nilai keragaman dapat diuji perbedaan tingkat nyatanya dengan menggunakan rumus sebagai berikut:

$$
\mathrm{t}=\frac{\mid \mathrm{H}_{1}-\mathrm{H}_{2} \|}{\sqrt{\operatorname{Var}\left(\mathrm{H}_{1}-\mathrm{H}_{2}\right)}}
$$

Keterangan : 
$t \quad:$ : t hitung

H' : Keanekaragaman jenis

Var H' : Varian keanekaragaman jenis

\section{HASIL PENELITIAN DAN PEMBAHASAN}

3.1. Gambaran Umum Lokasi Penelitian Kawasan Pegunungan Karst Sangkulirang-Mangkalihat berada di dua kabupaten yaitu Kabupaten Berau dan Kabupaten Kutai Timur. Sebagian besar kawasan Karst ini berada di wilayah Kabupaten Kutai Timur Meliputi wilayah Kecamatan Bengalon, Kaliorang, Sangkulirang, Kongbeng, Karangan dan Sandaran. Pada Kabupaten Berau lokasi sebaran batu kapur terdapat pada 6 Kecamatan yakni di Kecamatan Biduk-biduk, Kecamatan Batu Putih, Kecamatan Talisayan, Kecamatan Biatan, Kecamatan Tabalar dan Kecamatan Sambaliung. Jika dilihat secara lokasi dalam keberadaannya yang luas, lokasi sebaran batu kapur tersebut ada yang terdapat pada kawasan lindung dan ada yang terdapat pada kawasan budidaya.Kawasan ini merupakan penghasil jutaan liter air untuk beragam kehidupan flora, fauna dan manusia (Renosari.G. dan Ardiwijaya.R 2016).

\subsection{Letak Geografis}

Letak geografis Kabupaten Kutai Timur dan Kabupaten Berau yang dekat dengan Garis Khatulistiwa, menjadikan daerah ini memiliki iklim tropis yang memiliki curah hujan tinggi dengan hari hujan merata sepanjang tahun. Intensitas penyinaran matahari yang tinggi menjadikan suhu udara relatif tinggi sepanjang tahun dengan kelembaban udara yang tinggi pula.

\subsection{Curah Hujan}

Curah hujan cenderung tinggi sepanjang tahun, data dari Stasiun Meteorologi Kalimarau (2005-2016) menunjukkan bahwa curah hujan berkisar antara121,93- 271,54 $\mathrm{mm} / \mathrm{bulan}$ dengan jumlah hari hujan sebanyak 11-21 hari. Curah hujan terendah terjadi pada bulan Agustus yaitu sebesar 121,93 $\mathrm{mm} / \mathrm{bulan}$ dengan jumlah hari hujan rata-rata pada bulan tersebut 11 hari. Curah hujan terbesar terjadi pada bulan Januari sebesar $271,54 \mathrm{~mm} /$ bulan dengan jumlah hari hutan rata-rata pada bulan tersebut 21 hari. Bulan tersebut merupakan akhir dari musim penghujan dan awal masa pancaroba.

\subsection{Komposisidan Kekayaan Jenis}

Pohon

Dari hasil penelitian yang dilakukan, ditemukan sebanyak 162 jenis pohon yang tergabung ke dalam 41 famili dan 538 individu. Komposisi perolehan jenis pohon pada keenam lokasi penelitian dapat dilihat pada tabel dibawah ini: 
Tabel 2. Komposisi jenis pohon yang yang teridentifikasi pada Kawasan Hutan Gunung Kapur Sangkulirang-Mangkalihat

\begin{tabular}{|c|c|c|c|}
\hline Lokasi & Famili & jenis & JumlahIndividu \\
\hline Suaran & 18 & 39 & 80 \\
\hline Tondoyan & 16 & 32 & 66 \\
\hline Gergaji & 28 & 57 & 111 \\
\hline BiatanUlu & 19 & 38 & 108 \\
\hline LobangKelatak & 21 & 41 & 89 \\
\hline Biduk-biduk - Tl. Suaiaman & 20 & 41 & 84 \\
\hline Total & 41 & 162 & 538 \\
\hline
\end{tabular}

Keterangan : Nilai total pada family dan jenis bukan merupakan hasil penjumlahan, melainkan jumlah jenis dan family yang ditemukan pada keenam lokasi penelitian, sedangkan nilai total pada jumlah individu adalah hasil penjumlahan jenis pohon yang ditemukan pada lokasi penelitian

Komposisi jenis pohon yang ditemukan pada masing-masing lokasi penelitian bervariasi, dimana jumlah jenis yang paling tinggi diperoleh di gergaji dengan 57 jenis, 28 family dan yang terendah di Tondoyan dengan 32 jenis, 16 family. Selain itu secara keseluruhan terdapat 7 Family yang memiliki jumlah jenis relative banyak yaitu Meliaceae, Dipterocarpaceae, Annonaceae, Lauraceae, Euphorbiaceae dan Moraceae. Besarnya jumlah jenis tumbuhan yang ada pada masing-masing lokasi sangat berhubungan dengan kondisi lingkungannya. Hal ini juga disampaikan oleh (Wijana, 2014) bahwa komposisi spesies tumbuhan yang berbeda-beda dipengaruhi dari altitude, latitude, factor edafik, dan factor klimatik dari daerah kajian masing- masing. Selanjutnya menurut (Monk et al,2000).

\subsection{Potensi Vegetasi}

Dari hasil penelitian yang dilakukan, diperoleh potensi vegetasi tingkat pohon pada kawasan hutan gunung kapur Sangkulirang-Mangkalihat peroleh Individu (N/Ha) terbesar dilokasi hutan gunung kapur Gergaji dengan nilai individu 740/ha, sedangkan untuk nilai Basal Area terbesar diperoleh dilokasi hutan gunung kapur Lobangkelatak dengan nilai Basal area $54.14 \mathrm{~m}^{2} /$ ha dan untuk volume terbesar diperoleh dilokasi hutan gunung kapur Lobangkelatak dengan nilai volume $696 \mathrm{~m}^{3} / \mathrm{ha}$. Untuk lebih jelasnya dapat dilihat pada table berikut. 
Tabel 3. Potensi Vegetasi Tingkat Pohon Pada Kawasan Hutan Gunung Kapur SangkulirangMangkalihat

\begin{tabular}{lccc}
\hline \multicolumn{1}{c}{ Lokasi } & N/Ha & Basal Area/Ha & Volume/Ha \\
\hline Suaran & 533 & 44.04 & 451.99 \\
Tondoyan & 440 & 29.03 & 305.19 \\
Gergaji & 740 & 16.23 & 258.42 \\
Biatan & 720 & 50.21 & 631.86 \\
Lobang & 593 & 54.14 & 696.02 \\
Kelatak & & & \\
Biduk-biduk & 560 & 40.50 & 300.04 \\
Tl.sulaiman & & & \\
\hline
\end{tabular}

Dari tabel diatas dapat kita lihat potensi vegetasi tingkat pohon pada lokasi penelitian berbeda- beda pada setiap lokasi. Beragamnya potensi pohon pada masing-masing lokasi dipengaruhi oleh adanya pengaruh lingkungan tempat tumbuhnya, seperti kelembaban dan suhu dan tidak mampu atau kalah berkompetisi, seperti perebutan akan zat hara, sinar matahari dan ruang tumbuh dengan jenis-jenis lainnya yang sangat mempengaruhi pertumbuhan dari diameter batang pohon. Selain itu untuk lokasi tondoyan dan gergaji yang potensi vegetasi pohonnya tergolong kecil karena disebabkan karena pada kedua lokasi ini pernah terjadi kebakaran sehingga pada kedua lokasi tersebut tergolong dalam hutan sekunder sedangkan untuk lokasi Biduk-biduk Teluk Sulaiman kecilnya potensi pada daerah ini disebabkan oleh adanya aktivitas penebangan yang dilakukan oleh masyrakat setempat.
Besarnya nilai luas bidang dasar tidak mengikuti pola berbanding lurus di mana makin banyak pohon maka makin besar nilainya, hal ini disebabkan dalam perhitungan luas bidang dasar besarnya diameter dikuadratkan sehingga makin besar diameter akan memiliki nilai luas bidang dasar yang besar pula. Hal ini terlihat pada tabel 5, bahwa banyaknya pohon tidak menjamin akan nilai Basal Area yang tinggi pula.

\section{KESIMPULAN}

Dari hasil dan pembahasan di atas, dapat ditarik kesimpulan bahwa, Di enam lokasi penelitian kaya akan jenis, dimana berhasil didata sebanyak 164 jenis yang tergolong dalam 538 Individu dan 41 Famili, dengan indeks kekayaan tergolong baik, yaitu nilai indeks kekayaan (R1) di atas 5.Niai Indeks keanekaraman (H') pada lokasi penelitian tergolong tinggi berkisar 3,17 -3,51. 


\section{DAFTAR PUSTAKA}

Achmad, A."Rahasia Ekosistem Hutan Bukit Kapur". Brilian Internasional. Surabaya (2011)

Barbour GM, Burk JK, et all. "Terrestrial Plant Ecology". New York : The Benjamins/Cummings Publishing Company (1987).

Beynen, P. V and Townsend, K (2005).A disturbance index for karst environments. Jurnal Environmental Management 101116.

Haryono, E \&Adji, T.N. "Pengantar Geomorfologi dan $\mathrm{H}$ idrologi Karst”. Yogyakarta: Kelompok Studi Karst Fakultas Geografi UGM (2004).

Indriyanto."Ekologi Hutan. Bandar Lampung. PT. Bumi Aksara. Jakarta (2008).
Kurniawan, A. dan Parikesit, "Persebaran Jenis Pohon di Sepanjang Faktor Lingkungan di Cagar Alam Pananjung Pangandaran".Jawa Barat (2008).

Monk, K.A., Y, De Fretes., et al. "Ekologi Nusa Tenggara Dan Maluku". Jakarta: Prenhallindo (2000).

Renosari, G dan Ardiwijay R, 2016.The Nature Conservancy (TNC). Indonesia.http:www. nature. Or .id / blog / karst - sangkulirang mangkalihat - urat - nadi kehidupan - berau - dan kutaitimur.xml (diakses pada 10 April 2017).

Raguz, V. Karst and Water in it: A Literature Study on Karst in General and on Problems and Possibilities of Water Management in Karst in Particula". Sweden: Geobiosphere Science Center, Physical Geography and Ecosystems Analysis Lund University (2008) 
Sutiknodan Eko Haryono. 2000. Perlindungan fungsi kawasan karst. Makalah Seminar: Perlindungan Penghuni Kawasan Karst Masa Lalu, Masa Kini, dan Masa DatangTerhadap penurunan Fungsi Kualitas Lingkungan.
Wijana, N.2013.Pengelolaan hutan berbasis kearifan lokal di desa tigawasa kecamatan banjar, kabupaten buleleng. Seminar Nasional FMIPA Undiksha 47-6. 